\title{
Characterization of a Murine Model System to Study MicroRNA-147 During Inflammatory Organ Injury
}

\author{
Boyun Kim, ${ }^{1}$ Victor Guaregua, ${ }^{1}$ Xuebo Chen, ${ }^{1}$ Chad Zhao, ${ }^{2}$ Wanyi Yeow, ${ }^{1}$ Nathaniel K. Berg, ${ }^{1}$ \\ Holger K. Eltzschig, ${ }^{1}$ and Xiaoyi Yuan ${ }^{1,3}$
}

\begin{abstract}
(Received December 15, 2020; accepted January 26, 2021)
Abstract-Inflammatory organ injury and sepsis have profound impacts on the morbidity and mortality of surgical and critical care patients. MicroRNAs are small RNAs composed of 2025 nucleotides that have a significant contribution to gene regulation. MicroRNA-147 (miR147), in particular, has been shown to have an emerging role in different physiological functions such as cell cycle regulation and inflammatory responses. However, animal model systems to study tissue-specific functions of miR-147 during inflammatory conditions in vivo are lacking. In the present study, we characterize miR-147 expression in different organs and cell types. Next, we generated a transgenic mouse line with a floxed miR-147 gene. Subsequently, we used this mouse line to generate mice with whole-body deletion of $m i R$ $147\left(\operatorname{miR}-147^{-/}\right)$by crossing "floxed" miR-147 mice with transgenic mice expressing Cre recombinase in all tissues (CMVcre mice). Systematic analysis of $m i R-147^{-1-}$ mice demonstrates normal growth, development, and off-spring. In addition, deletion of the target gene in different organs was successful at baseline or during inflammation, including the heart, intestine, stomach, liver, spleen, bone marrow, lungs, kidneys, or stomach. Moreover, $m i R-147^{--}$mice have identical baseline inflammatory gene expression compared to C57BL/6 mice, except elevated IL-6 expression in the spleen (7.5 fold, $p<$ $0.05)$. Taken together, our data show the successful development of a transgenic animal model for tissue and cell-specific deletion of miR-147 that can be used to study the functional roles of miR-147 during inflammatory organ injury.
\end{abstract}

KEY WORDS: Inflammation; Organ injury; MicroRNA; Transgenic mouse model; MicroRNA-147.

\section{INTRODUCTION}

\footnotetext{
${ }^{1}$ Department of Anesthesiology, McGovern Medical School, University of Texas Health Science Center at Houston, 6431 Fannin Street, Houston, TX 77030, USA

${ }^{2}$ McGovern Medical School, University of Texas Health Science Center at Houston, Houston, TX 77030, USA

${ }^{3}$ To whom correspondence should be addressed at Department of Anesthesiology, McGovern Medical School, University of Texas Health Science Center at Houston, 6431 Fannin Street, Houston, TX 77030, USA. E-mail: Xiaoyi.yuan@uth.tmc.edu
}

Inflammation is commonly observed in organ injuries including acute respiratory distress syndrome (ARDS) [13], myocardial infarction [4], acute kidney injury [5-7], and in sepsis and septic shock [8,9], which contribute significantly to the mortality and morbidity of surgical or critical care patients. Sepsis and septic shock alone affect more than 31.5 million patients globally each year [8]. 
Different cell populations play a distinct role in the pathogenesis of inflammatory organ injuries. For example, innate immune cells such as macrophage and neutrophils are involved in the acute phase of inflammation in response to the pathogen-associated molecular patterns (PAMP) and danger-associated molecular patterns (DAMP) and contribute to the production of early inflammatory cytokines including tissue necrosis factor (TNF) and interleukin 1 (IL-1) [10]. Endothelial cells and epithelial cells could further respond to DAMP to promote tissue injury and organ dysfunction [10]. So far, the treatment option of inflammatory organ injury involves correcting the underlining causes and supportive care [11]. Thus, understanding the pathogenesis and the search for novel therapeutic targets for inflammatory organ injury is at the center of attention. To this front, several animal models have been developed to study pathophysiology and therapeutic targets of systemic inflammation and organ dysfunction [12]. For example, cecal ligation and puncture (CLP) is one of the most commonly used models to induce systemic inflammation and organ injury mainly caused by multimicrobial infection [13].

MicroRNAs are small RNAs ranging from 20 to 25 nucleotides that are crucial for post-transcriptional gene regulation. So far, there are more than 2000 microRNAs identified in the human genome according to the most recent miRBase database (http:/www.mirbase.org/). The main role of microRNAs is to regulate target gene expression through interaction with the untranslated region (UTR) [14]. It is estimated that microRNAs could target $60 \%$ of the human genes [15], indicating the critical role of microRNAs in many physiological and pathological conditions. Previous studies have suggested that microRNAs play crucial roles in development, cell cycle regulation, inflammatory responses, and many other physiological processes [14, 16-18]. For example, miR-223 functions as a regulator of macrophage and neutrophil differentiation and activation [19]. A recent study identified the shuttling of miR-223 from neutrophil to alveolar epithelial cells to provide tissue protection during acute lung injury [20], suggesting diverse mechanisms of action for microRNAs. In the clinic, microRNAs could be therapeutically targeted via several approaches [21]. Specifically, microRNA overexpression is achieved by the delivery of microRNA mimetics, while microRNA inhibition is achieved by inhibitors such as the locked nucleic acid (LNA) [21]. For example, miR-122 has been identified as an enhancer for hepatitis $\mathrm{C}$ virus (HCV) replication via binding to the $5^{\prime}$ UTR of the viral genome [22]. MiR-122 LNA has been developed and studied by phase III clinical trials as HCV therapy showing promising results [23, 24]. Stemming from the functional diversity and the ease of therapeutic targeting, investigations on microRNAs have been intensive. Thus, developing mouse models to pinpoint the specific contribution of microRNAs in a particular tissue or cell type is of great importance.

MiR-147 (hsa-miR-147b or mmu-miR-147-3p) is located at chromosome 15 in humans and chromosome 2 in mouse. It has been continuously gaining attention as a key regulator of cell cycle progression and inflammatory responses by in vitro and pharmacological studies in vivo [25-32]. For example, miR-147 has been identified as the top upregulated microRNA in lung cancer cells that are tolerant to epidermal growth factor receptor inhibitor, and it orchestrates the metabolic shift of cancer cells for drug tolerance [25]. Another earlier study indicated that miR147 is induced by toll-like receptor stimulation in macrophages and it is involved in the regulation of inflammatory responses [26]. These studies, along with many others, support the emerging role of miR-147 in the control of many biological processes both in homeostasis and in pathological conditions. Here, we developed a transgenic mouse line using the Cre-flox system for germline and conditional targeting of miR-147 in vivo. The generation of this mouse line will facilitate the study of tissue-/cellspecific contribution of miR-147 in inflammatory organ injury.

\section{MATERIALS AND METHODS}

Animals. Animal procedures were approved by the Institutional Animal Care and Use Committee at the University of Texas Health Center (UTHealth) at Houston. C57BL/6J (wild-type), miR-147 $7^{\text {loxP/loxP }}$, CMVcre mice were purchased from Jackson Laboratories (Bar Harbor, $\mathrm{ME})$. All mice were housed and bred in a specific pathogen-free facility with a 12-h:12-h light:dark cycle at the Center for Laboratory Animal Medicine and Care at the UTHealth. Both gender mice with age between 8 and 12 weeks were used in this experiment. To produce wholebody deficiency of $m i R-147, m i R-147^{\text {loxP/loxP }}$ mice were crossbred with $\mathrm{CMVcre}^{+}$mice to generate $\operatorname{miR}-147^{\text {loxP }}$ ${ }^{\text {loxP }} \mathrm{CMVcre}^{+}$mice $\left(\mathrm{miR}-147^{-/-}\right)$.

CLP Model. To establish endotoxin-induced organ injury models, we performed cecal ligation and puncture (CLP) procedure. Mice were anesthetized with 3-5\% inhaled isoflurane for induction and $1-3 \%$ for maintenance. The cecum was ligated with 4-0 sterile suture at $1 \mathrm{~cm}$ from the end, and was punctured twice with a $20 \mathrm{G}$ needle. A 
small amount of feces was extracted with around $2 \mathrm{~mm}$ diameter. Sham operation was conducted in the same way without ligation and puncture. Buprenorphine SR was administrated via subcutaneous injection after surgery to reduce pain, and $500 \mu \mathrm{l}$ of sterile and prewarmed saline was injected to protect from dehydration. All procedures are performed under sterile conditions. The organs were collected $24 \mathrm{~h}$ after the procedure.

Cell Lines. HEK293, HMEC1, T84, A539, Calu3, HK-2, Caco, HL60, and THP1 cells were purchased from ATCC and cultured according to ATCC recommended conditions. Human cardiomyocytes (HCM) and human pulmonary alveolar epithelial cells (HPAEpiC) were purchased from ScienCell (Catalog \#6200 and \#3200, respectively) and cultured according to the manufacturer's instruction. Human monocyte-derived macrophages (MDM) were differentiated from monocytes as previously described [33], using monocytes isolated from peripheral blood collected from healthy volunteers.

$T$ Cell Differentiation. Naïve CD4 T cells were isolated from spleens dissected from 8- to 12-week-old C57BL/6J mice using the STEMCell Naïve CD4 T cell isolation kit according to the manufacturer's instruction. Isolated cells were cultured in a concentration of 2-2.5 $\mathrm{million} / \mathrm{ml}$ in complete RPMI with L-glutamine supplemented with $10 \%$ heat inactivated FBS and antimicrobial reagents. T cell differentiation to Th0/Th1/Th2/Th17/Treg condition was as previously described [34]. Cells were cultured for $72 \mathrm{~h}$ and washed with PBS. After centrifugation, cell pellet was lysed by Trizol reagent for RNA isolation.

Isolation of Blood Neutrophils, Lymphocytes, and Monocytes. Neutrophil was isolated from blood from 8to 12 -week-old $\mathrm{C} 57 \mathrm{BL} / 6 \mathrm{~J}$ mice as previously described [20]. Lymphocytes were isolated from blood from 8- to 12week-old C57BL/6J mice as previously described [35]. Monocytes were isolated from blood from 8- to 12-weekold C57BL/6J mice using EasySep ${ }^{\mathrm{TM}}$ Mouse Monocyte Isolation Kit from STEMCELL Technologies according to the manufacturer's recommended protocol. After centrifugation, cell pellet was lysed by Trizol reagent for RNA isolation.

Isolation of Alveolar Epithelial Cells. Alveolar epithelial cells were isolated as previously described [36]. In brief, 8to 12 -week-old C57BL/6J mice were euthanized by overdose of pentobarbital. After opening up the chest cavity, lungs were perfused with $10 \mathrm{ml}$ of PBS and a small incision was made at the trachea for the insertion of $20 \mathrm{G}$ blunt ended catheter. $1.5 \mathrm{ml}$ of 5 unit $/ \mathrm{ml}$ dispase in DMEM/F12 media was instilled intratracheally via the catheter and followed by $300 \mu \mathrm{l}$ of $1 \%$ low melting point agarose in PBS. Lungs were removed and incubated in $0.5 \mathrm{ml}$ of dispase for $45 \mathrm{~min}$ at room temperature. After the incubation, lung tissues were cut into small pieces and rotate for $15 \mathrm{~min}$ at $4^{\circ} \mathrm{C}$. Digested tissues run through a 70-micron cell strainer and biotinylated antibodies for CD16/32, TER119, CD 45, and CD90 were added. Alveolar epithelial cells were negatively selected using streptavidin labeled magnetic beads. The resulting cells were incubated for $2 \mathrm{~h}$ to remove fibroblast. The cell pellet was lysed by Trizol reagent for RNA isolation.

Isolation of Colon Epithelial Cells. Colon epithelium was isolated from 8- to 12 -week-old C57BL/6J mice as previously described [37]. Cell pellet was lysed by Trizol reagent for RNA isolation.

Isolation of Renal Tubule Cells. Kidney tubules were isolated according to a modified protocol described previously [38]. Mice were euthanized by high dose of pentobarbital sodium and the kidneys were reperfused with icecold PBS. The kidneys were washed with ice-cold PBS twice and were chopped into small pieces on ice. The chopped tissues were enzymatically dissociated with collagenase type II $(0.25 \mathrm{mg} / \mathrm{ml}$; Worthington $)$ using a gentleMACS tube (Miltenyi Biotec). The tissue was incubated and dissociated in gentleMACS ${ }^{\mathrm{TM}}$ Octo Dissociator (Miltenyi Biotec) at $37^{\circ} \mathrm{C}$ for $30 \mathrm{~min}$. After enzymatic reaction, collagenase activity was inhibited by adding one volume of Renal Epithelial Growth Medium 2 (PromoCell). To collect tubular cells, the dissociated kidney was centrifuged at $50 \times \mathrm{g}$ for $5 \mathrm{~min}$. First pellet was resuspended with Renal Epithelial Growth Medium 2 and the supernatant was centrifuged again at $50 \times \mathrm{g}$ for $5 \mathrm{~min}$. Second pellet was resuspended in the same medium. First and second pellets were combined and used for analyses.

Quantitative Real-time Polymerase Chain Reaction. Total RNA was isolated from cultured cells and mouse tissues using a Trizol reagent (Ambion, Life Technologies) according to the manufacturer's instructions. Reverse transcription was carried out from $50 \mathrm{ng}$ of total RNA using a HighCapacity cDNA RT kit (Applied Biosystems, Thermo Fisher Scientific). TaqMan real-time PCR assay was performed to detect Il-6, Cxcll, and $18 s$ (internal control). TaqMan ${ }^{\mathrm{TM}}$ Gene Expression Assay (FAM): 18s (catalog number: 4351368, Assay ID: Hs99999901_s1); Il-6 (catalog number: 4351370, Assay ID: Mm00446190_m1); Cxcll (catalog number: 4351370, Assay ID: Mm04207460_m1). For miRNA detection, quantitative PCR was conducted in twostep PCR using TaqMan MicroRNA Assay. First, reverse transcription (RT) was performed from 10 ng total RNA using miR-147 and U6 snoRNA (internal control) primers on a Bio-Rad T100 Thermal Cycler. Second, the RT-PCR product was amplified using TaqMan MicroRNA Assay 
plus the TaqMan Universal PCR Master Mix on Bio-Rad CFX384 real-time system. The relative expressions of target genes were calculated using $2^{-\Delta \Delta \mathrm{Ct}}$ method after normalizing by $18 s$ or U6 snoRNA. TaqMan ${ }^{\mathrm{TM}}$ MicroRNA Assay: miR-147 (Catalog \#: 4440887, Assay ID: 002262); U6 snoRNA (Catalog \#: 4440888, Assay ID: 001973).

Histopathological Analysis. Histological comparison of major organs including the brain, heart, liver, lung, stomach, intestine, spleen, and kidney was performed in 8- to 12week-old, sex- and age-matched C57BL/6J mice and $m i R$ $147^{-}$mice as previously described [39]. After harvesting, tissues were fixed in 10\% formaldehyde for $24-48 \mathrm{~h}$ and paraffin-embedded. Five-micrometer sections were cut and stained with hematoxylin and eosin. Pictures were taken from the slides using a Leica microscope.

Statistical Analysis. All data included were shown as mean \pm standard error (SEM) of the mean. Data following normal distribution and have equal variances were compared using parametric two-sample unpaired $t$ tests. Data that are not normally distributed were analyzed using nonparametric two-sample unpaired $t$ tests using MannWhitney rank-sum tests. Comparison of three or more groups was achieved by one-way ANOVA and corrected for multiple comparisons. Detailed information of statistical analysis for each experiment shown was included in the figure legend. Statistical analyses were performed using GraphPad Prism software.

\section{RESULTS}

\section{MiR-147 Expression in Different Cell Lines, Primary Cells, and Organs}

Previous studies have suggested the functional role of miR-147 in many physiological processes including cell cycle regulation and metabolism [25-32]. Here, the expression pattern of miR-147 across different cells and organs is investigated by RT-qPCR. Firstly, we measured the expression level of miR-147 by RT-qPCR in different human cell lines (Fig. 1a) and found relatively high expression levels of miR-147 in T84, A549, and Calu 3 cells. The miR-147 levels in primary cells including human cardiomyocytes (HCM), human monocytederived macrophages (MDM), and human pulmonary alveolar epithelial cells (HPAEpiC) are further investigated (Fig. 1b). To study the miR-147 level across different organs, we harvested different organ compartments including the bone marrow, brain, heart, intestine, kidney, liver, lung, spleen, and stomach from C57BL/6J (WT) mice, and measured the miR-147 expression by RT-qPCR. MiR-147 is mostly enriched in the intestine, stomach, and heart tissue (Fig. 1c). Subsequently, different types of epithelial cells were isolated from C57BL/6J mice and higher miR-147 levels were observed in the colon epithelial cells compared to the alveolar epithelial cells and kidney tubule epithelial cells (Fig. 1d). Furthermore, no significant differences in miR-147 expression were observed in several types of blood immune cells including neutrophils, lymphocytes, and monocytes from the peripheral blood of C57BL/6J mice (Fig. 1e). Finally, there are no significant changes in the miR-147 levels across the different $\mathrm{T}$ helper differentiation conditions when naïve CD4 $\mathrm{T}$ cells isolated from the spleen of C57BL/6J mice are differentiated into $\mathrm{T}$ helper 0 (Th0), $\mathrm{T}$ helper 1 (Th1), T helper 2 (Th2), T helper17 (Th17), and regulatory $\mathrm{T}$ (Treg) cells in vitro (Fig. 1f).

\section{The Expression Level of MiR-147 After CLP}

After having shown the expression level of miR-147 under baseline conditions across different organs, we next investigated the expression of miR-147 under systemic inflammatory conditions. To achieve systemic organ inflammation, CLP or sham procedure was performed in 8- to 10week-old C57BL/6J mice and major organs including the brain, heart, intestine, kidney, liver, lung, spleen, and stomach were harvest $24 \mathrm{~h}$ after CLP. Firstly, to understand the inflammatory conditions in each organ, the expression level of Cxcll in these organs was assessed by RT-qPCR in the CLP and sham group and significant induction of $\mathrm{Cxcll}$ was found in all of the organs (Fig. 2a). In addition, previous studies have indicated an upregulation of $I l 6$ in the CLP models. Thus, we compared the expression level of $I l 6$ in these organs by RT-qPCR in the CLP and sham group and found significant induction of these $I l 6$ in the majority of the organs except the brain and intestine (Fig. 2b). These results indicate profound multi-organ inflammation in the CLP group. Finally, the expression pattern of miR-147 in inflamed organs was further measured by RT-qPCR. Surprisingly, miR-147 is induced in the lung, kidney, and stomach while decreased in the brain following the CLP procedure when compared to the sham group (Fig. 2c). Taken together, these studies indicated strong systemic inflammation in all major organs following CLP, and miR-147 is selectively upregulated in the lung, kidney, and stomach while downregulated in the brain. 
a

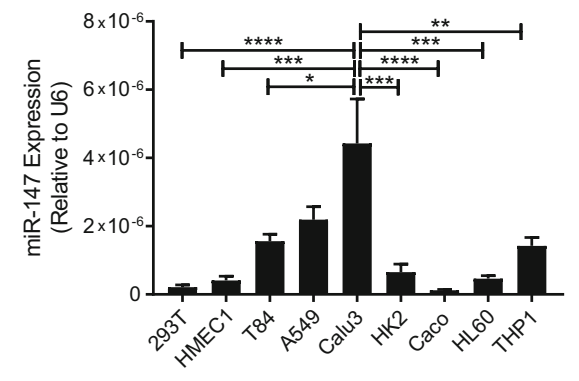

d

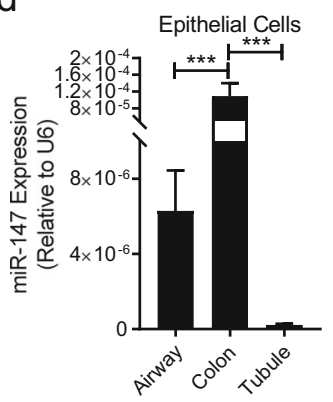

b

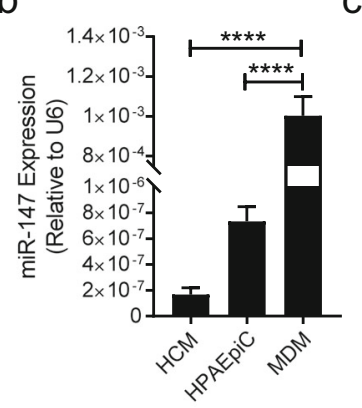

C

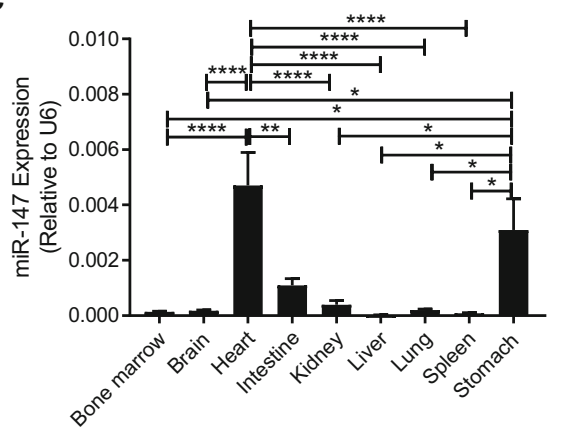

e

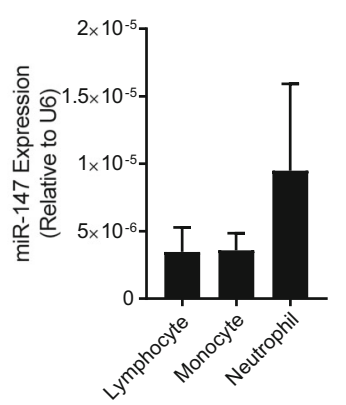

$f$

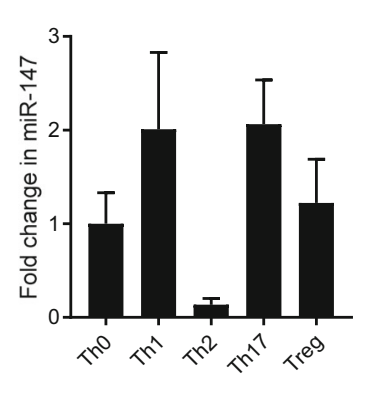

Fig. 1. MiR-147 expression across different cell lines, tissue, and cells. a Transcript level of miR-147 in various human cell lines (kidney-derived cell lines including HEK293T and HK2; endothelial cell line, HMEC1; colon-derived cell lines including T84, Caco2, and HL60; lung-derived cell lines including A549 and Calu3; peripheral blood-derived cell line, THP1). Expression level was normalized to U6 snoRNA. b Transcript level of miR-147 in human primary cells including human cardiomyocytes (HCM), human pulmonary alveolar epithelial cells (HPAEpiC), and human monocyte-derived macrophages (MDM). Expression level was normalized to U6 snoRNA. c Screening of miR-147 expression in different organs collected from C57BL/6J mice. Expression level was normalized to U6 snoRNA. d Transcript level of miR-147 in murine primary epithelial cells derived from airway, colon, and renal tubules. Expression level was normalized to U6 snoRNA. e Transcript level of miR-147 in immune cells such as lymphocytes, monocytes, and neutrophils isolated from the peripheral blood of C57BL/6J mice. Expression level was normalized to U6 snoRNA. f Transcript level of miR-147 in Th0, Th1, Th2, Th17, and Treg cells differentiated from naïve CD4 T cells of C57BL/6J mice. Data was normalized to Th0. All graphs represent mean \pm SEM. $* P<0.05$, $* * P<0.01$, $* * * P<0.001, * * * * P<0.0001$ by one-way ANOVA with Bonferroni's multiple comparisons.

\section{Strategy for the Generation of MiR-147 Floxed Mice}

To address the function of miR-147 during organ injury, we generated a novel transgenic mouse line with a floxed miR-147 gene. Utilizing the Cre-loxP system, these mice allow us to generate mice with germline deletion of miR-147 ( $\mathrm{miR}-14 \mathrm{~T}^{-1}$ ) mice. Gene targeting of miR-147 conditional knockout was first established in Bruce4 C57BL/6 embryonic stem (ES) cells. To generate miR147 conditional mice, a 114-bp region encompassing the miR-147 gene was floxed with loxP sites (Fig. 3a). An FRT-flanked neo cassette was also inserted within the floxed region for targeted ES cell selection by neomycin. Correctly targeted ES cells were confirmed by Southern blotting with Neo and 3' probes (Fig. 3b). Subsequently, one of the clones with correct targeting (I-IC7) was selected for the generation of chimera mice. Breeding of chimera mice to flipase (flp) mice resulted in flp-mediated recombination at the FRT sites to delete the neo cassette. Litter from the mating of chimera and flipase mice was confirmed by Southern blot (Fig. 3c). These mice have been crossbred with CMVcre for the generation of miR$147^{-/-}$mice. $m i R-147^{-/}$allele was confirmed by genotyping on DNA isolated from tail snip. The primer sequence and PCR protocol are shown in Fig. $3 \mathrm{~d}$ and e. From the representative gel picture shown in Fig. 3f, the deletion band was successfully detected in the animals. Heterozygous mice carrying miR-147 deletion allele were further bred to generate homozygous $m i R-147^{\prime-}$ mice.

\section{Confirmation of MiR-147 Knockout and Breeding Characteristics of $\mathrm{miR}-147^{-/}$Mice}

After the identification of $m i R-147^{-1-}$ mice, we pursue to further confirm the knockout of miR-147 under inflammatory conditions and define the breeding 
a
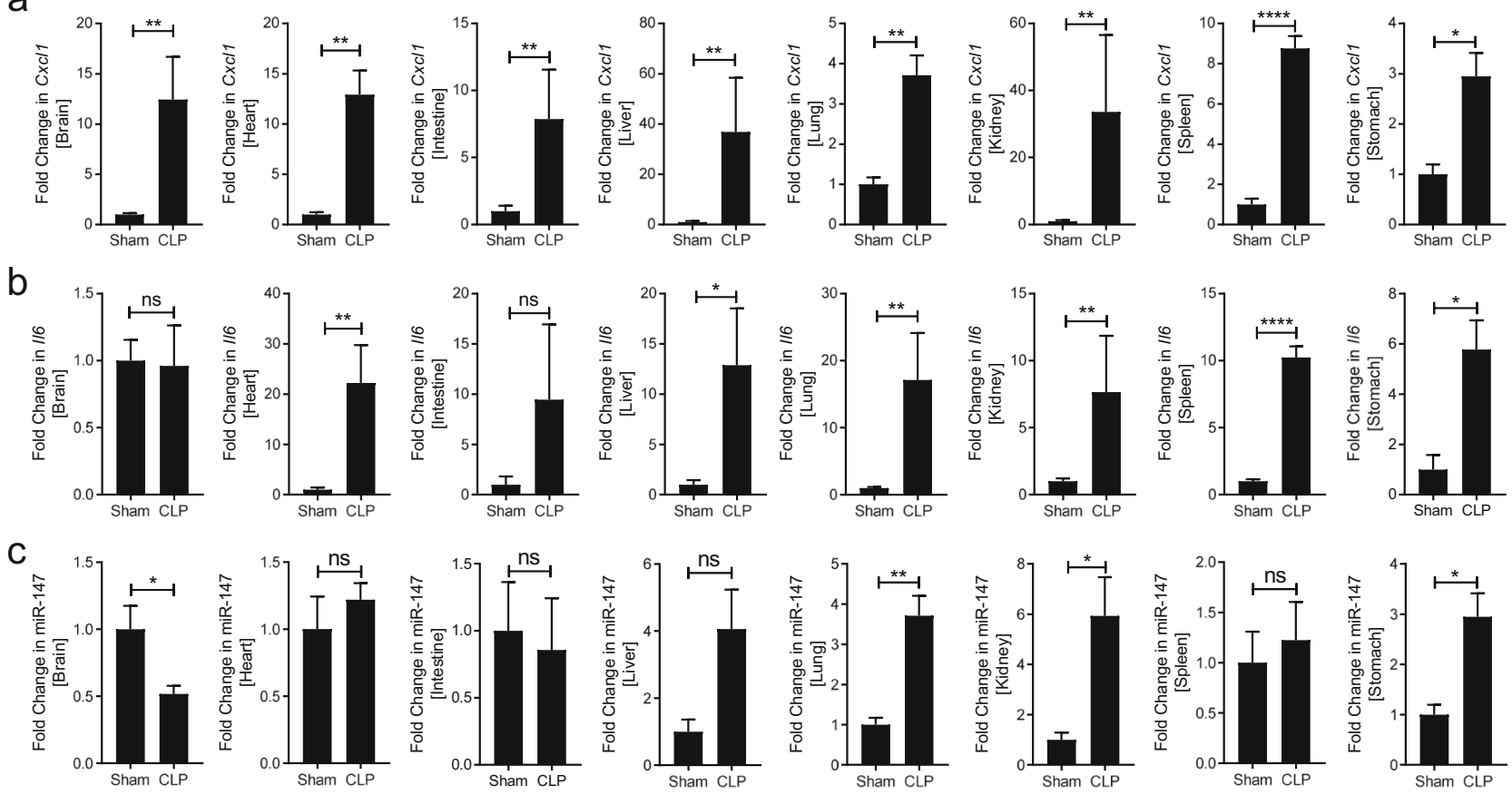

Fig. 2. Organ inflammation and miR-147 levels after CLP. CLP was conducted on 8- to 12-week-old C57BL/6J mice, and the indicating organs were collected in 24 h. a, b Induction of inflammatory genes including Cxcll and Il6 in CLP group. c Relative transcript level of miR-147 in CLP group compared to sham group. All graphs are presented as mean \pm SEM. $* P<0.05$, $* * P<0.01$, $* * * *<0.0001$ relative to sham, by Mann-Whitney test.

characteristics. Firstly, to confirm the knockout of miR147 , several major organs including the brain, heart, intestine, kidney, liver, lung, spleen, and stomach were harvested from WT or $m i R-147^{-/}$mice under baseline condition. The expression level of miR-147 was assessed by RTqPCR and the result indicated that miR-147 is successfully deleted in all major organs (Fig. 4a). To investigate the knockout efficiency of miR-147 under inflammatory conditions, WT or $m i R-147^{-/}$mice were exposed to CLP. Tissues showing significant upregulation of miR-147 during CLP, including the lung, kidney, and stomach, were harvest $24 \mathrm{~h}$ later for the analysis of miR-147 expression. miR-147 ${ }^{-/}$mice showed complete abolishment of miR147 levels compared to WT mice (Fig. 4b), indicating successful knockout of miR-147 during inflammatory conditions. Next, the reproductive performance and growth curves were assessed in $m i R-147^{-/}$mice. A total of 30 mice in the WT group and 29 mice in the $m i R-147^{-/}$were born in the study period. There are no significant differences in litter size and gender ratio (Fig. 4c). The weight of each mouse from the WT and $m i R-147^{-/}$ groups was recorded for the generation of weight curve. There is no significant difference in weight gain comparing WT and miR-147 as indicated in the growth curve (Fig. 4d). Furthermore, when separated based on gender, the weight curves are similar between $\mathrm{WT}$ and $m i R-147^{-/-}$ mice (Fig. 4e, f). Overall, the $m i R-147^{-/-}$mice show a successful knockout of miR-147 under inflammatory conditions and the breeding or growth of $m i R-147^{-/}$mice has similar characteristics compared to WT animals.

\section{Baseline Inflammation in $\operatorname{miR}-147^{-/-}$Mice}

After confirming the successful knockout of miR-147 in several organs following CLP, we next investigated the baseline inflammation in major organs and tissues to further characterize $m i R-147^{-/}$mice. For this purpose, we harvested organs and tissues including the bone marrow, brain, heart, intestine, kidney, liver, lung, spleen, and stomach, from age- and gender-matched WT or miR$147^{-/}$mice and measured the expression level of Cxcll and $I l 6$ by RT-qPCR. Statistically significant differences were not detected in the expression level of Cxcll in different organs or tissues when comparing WT and $m i R$ $147^{-/}$mice (Fig. 5a). However, the Il6 level is upregulated in the spleen from $\mathrm{miR}-147^{-/}$mice compared to that from WT mice, suggesting potential increases in the baseline inflammation in the spleen resulted from miR- 

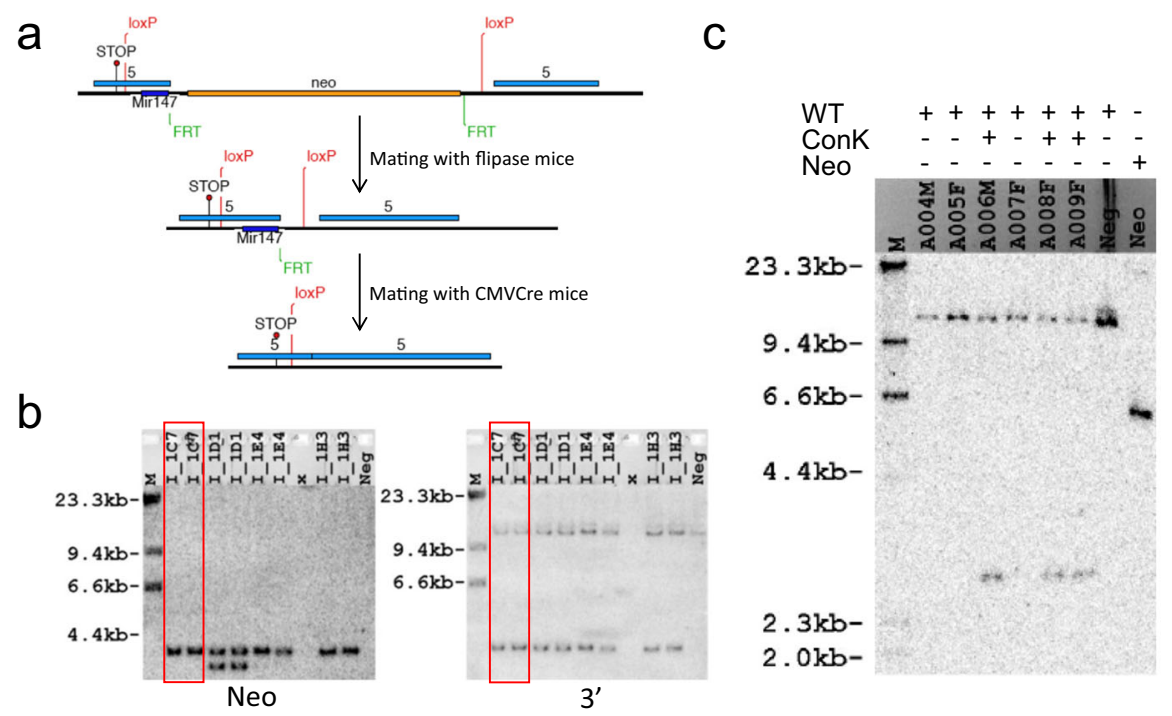

\begin{tabular}{|c|c|}
\hline Step & Procedure \\
\hline 1 & $95^{\circ} \mathrm{C} 2 \mathrm{~min}$ \\
\hline 2 & $9520 \mathrm{sec}$ \\
\hline 3 & $65^{\circ} \mathrm{C} /-.515 \mathrm{sec}$ \\
\hline 4 & $68^{\circ} \mathrm{C} 10 \mathrm{sec}$ \\
\hline 5 & Go to $2 \times 10$ \\
\hline 6 & $95^{\circ} \mathrm{C} 45 \mathrm{sec}$ \\
\hline 7 & $62^{\circ} \mathrm{C} 45 \mathrm{sec}$ \\
\hline 8 & $\begin{array}{l}72^{\circ} \mathrm{C} 1 \min 30 \\
\text { sec }\end{array}$ \\
\hline 9 & Go to $6 \times 28$ \\
\hline 10 & $72^{\circ} \mathrm{C} 2 \mathrm{~min}$ \\
\hline 11 & $4^{\circ} \mathrm{C}$ forever \\
\hline
\end{tabular}

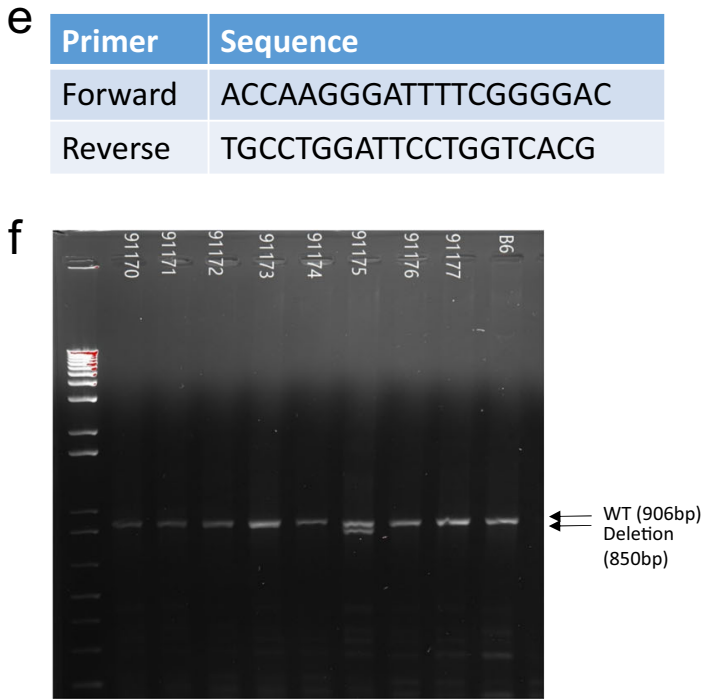

Fig. 3. Strategy for the generation of miR-147 floxed mice and $m i R-147^{-1}$ mice. a Schematic illustration for the generation of miR-147 conditional knockout mice. b Southern blotting with Neo and 3' probes to confirm targeted ES cells. I-IC7 (lane 1,2) was selected for chimera generation. $\mathbf{c}$ Southern blot

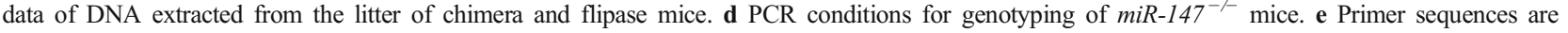
complementary to miR-147 allele. f Gel image from PCR-based genotyping to detect deletion of miR-147 allele.

147 deletion (Fig. 5b). Furthermore, we performed histological analysis on major organs including the brain, heart, intestine, kidney, liver, lung, spleen, and stomach, from age- and gender-matched WT or $m i R-147^{-1}$ mice by $\mathrm{H} \& \mathrm{E}$ staining. From the histological analysis, we did not observe significant abnormality in $m i R-147^{-/-}$mice when compared to WT animals (Fig. 5c). Taken together, these

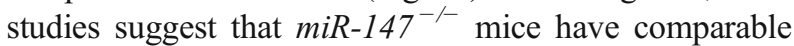
baseline inflammation and histological characteristics in major organs with WT animals, except for an elevated $I l 6$ expression in the spleen.

\section{DISCUSSION}

The present study aimed at establishing transgenic animal models to study miR-147 in organ injury. Previous studies had indicated a crucial role of miR-147 in key biological processes such as cell cycle regulation and inflammatory response. Thus, we investigated miR-147 expression levels in different cell lines, different organs, and different immune cell populations under baseline conditions. Following organ injury achieved by CLP, we observed systemic inflammation across all examined organs 
a
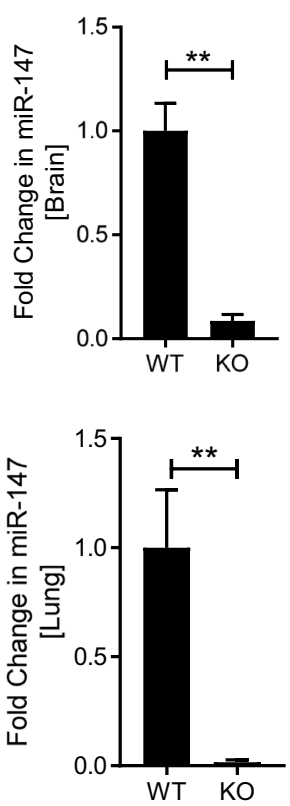

b

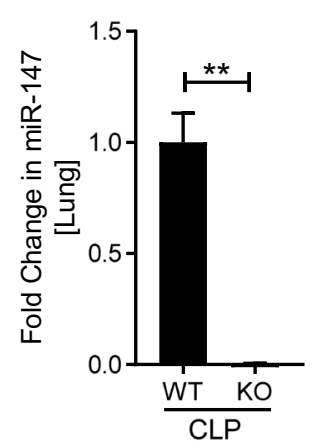

d

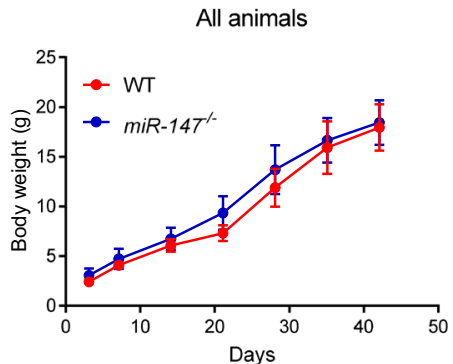

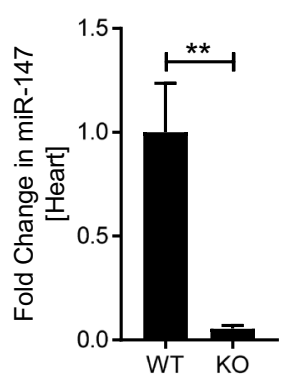
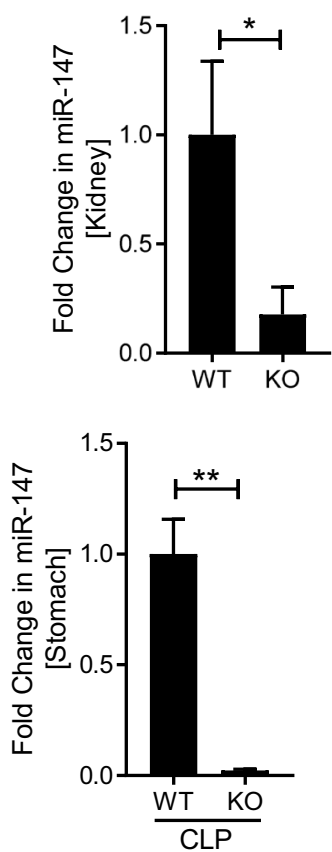

e

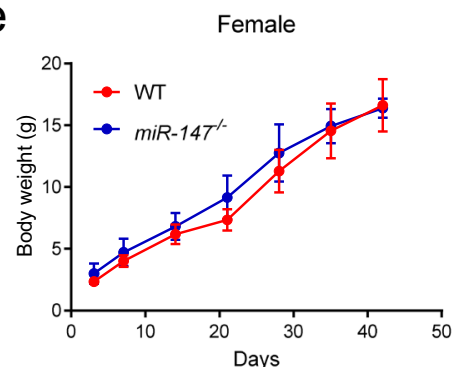

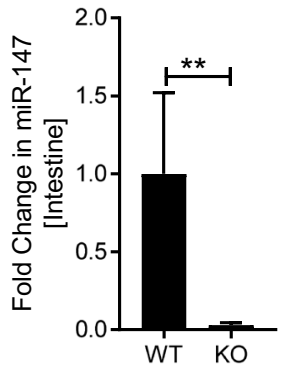
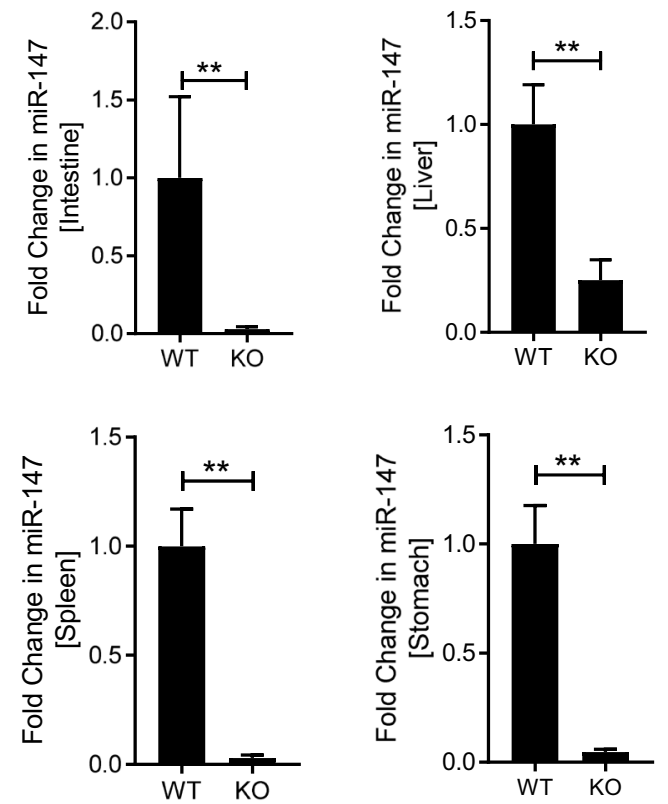

C

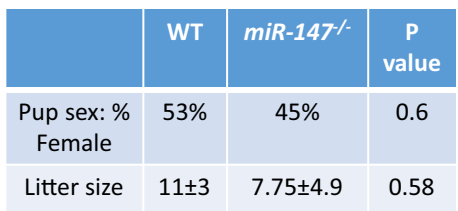

f

Male

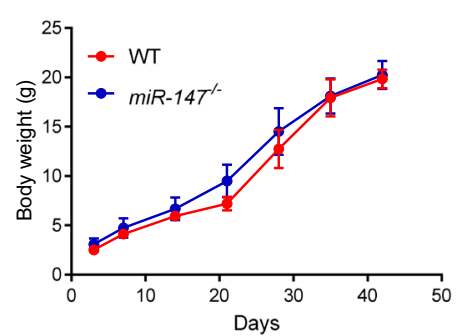

Fig. 4. Confirmation of miR-147 KO in various tissues and breeding characteristics and growth curve of $m i R-147^{\prime-}(\mathrm{KO}) \mathrm{mice}^{\circ}$ a Basal transcript level of miR-147 in the brain, heart, intestine, liver, lung, kidney, spleen, and stomach from C57BL/6J (WT) and $m i R-147^{\prime-}$ mice $(\mathrm{KO})(n=6 /$ group). b Transcript level of miR-147 in the lung, stomach, and kidney from WT and $m i R-147^{-1}$ mice following CLP procedure ( $n=6$ for WT; $n=5$ for KO mice). $\mathrm{c}$ Comparison of gender ratio and average litter size from WT and KO mice that were used for the present study. $P$ value from Fisher's exact test and unpaired $t$ test, respectively. d Growth curve based on body weight of all animals from WT and KO mice over 42 days. e Growth curve based on body weight of females from WT and KO mice. $\mathbf{f}$ Growth curve based on body weight of males from WT and KO mice. Graphs for mRNA expression represent mean \pm SEM and growth curves represent mean $\pm \mathrm{SD}$. $* P<0.05$, $* * P<0.01$ relative to WT, by Mann-Whitney test. 
a

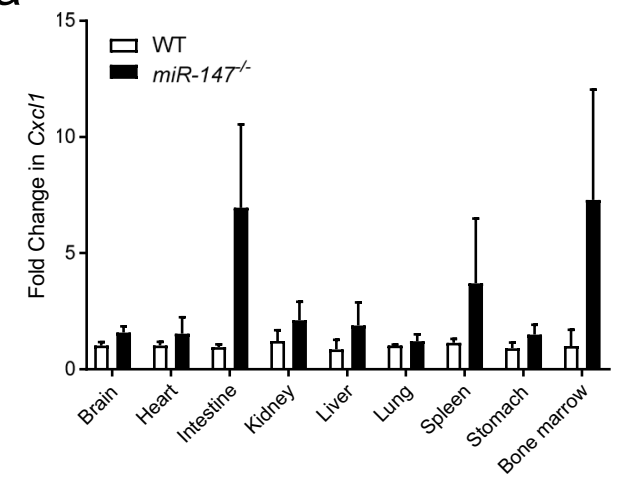

C

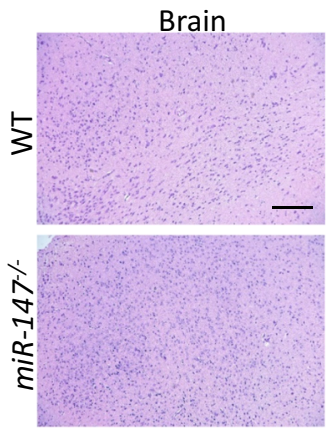

Lung
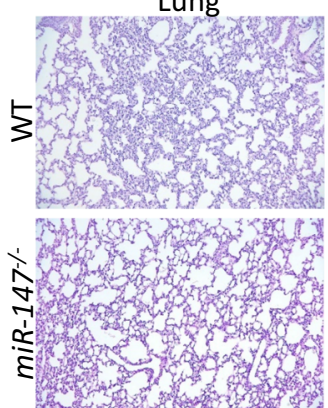

b
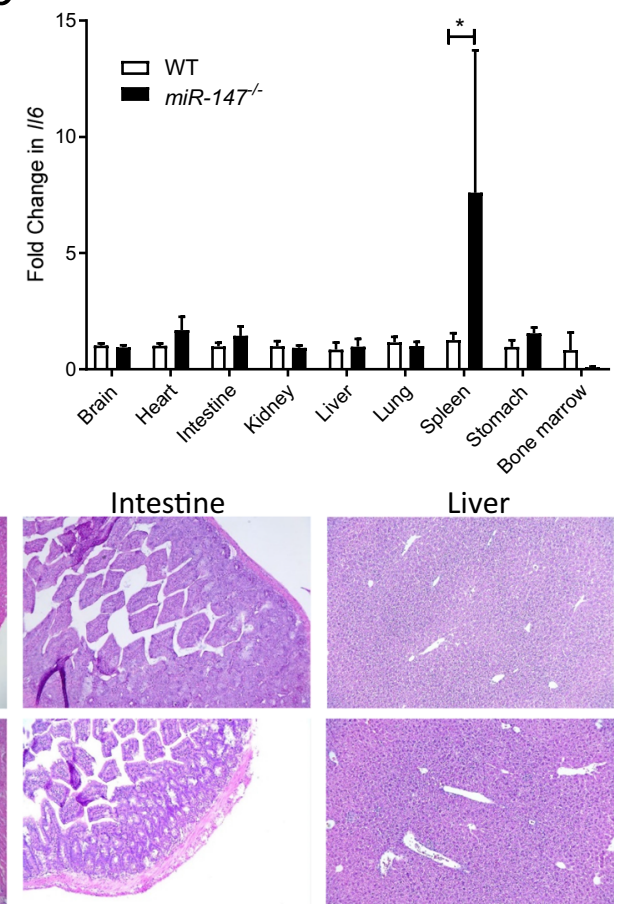

Spleen
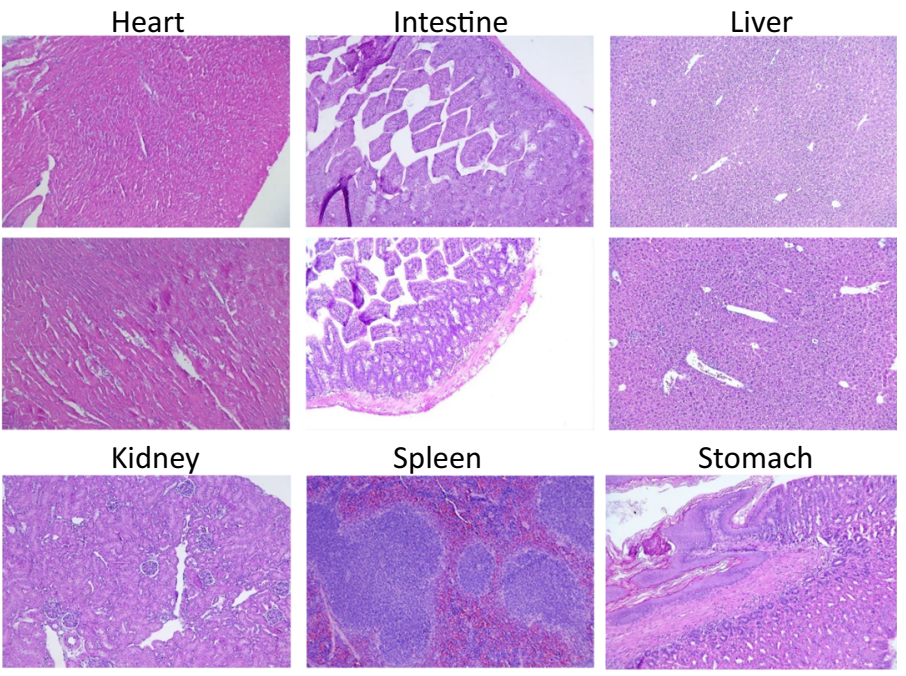

Stomach

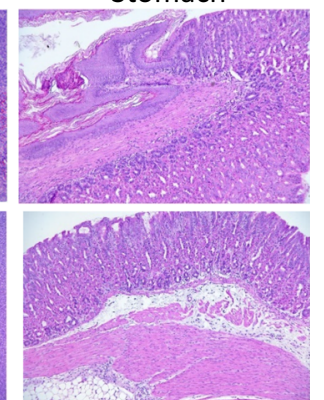

Fig. 5. Characterization of $m i R-147^{\prime-}$ mice. a, b Baseline mRNA expression level of inflammatory genes including Cxcll and $I l 6$ in various organs isolated from WT and $m i R-147^{-}$mice (KO). c Representative images of H\&E staining from mouse tissues including the brain, heart, intestine, liver, lung, kidney, spleen, and stomach to compare histology of WT and $m i R-147^{1-}$ mice (scale bar: $200 \mu \mathrm{m}$ ). All graphs represent mean \pm SEM. $* P<0.05(n=6$ mice/group) relative to WT, by two-way ANOVA with Bonferroni's multiple comparisons.

and miR-147 upregulation in the lung, stomach, and kidney. Furthermore, to address the function of miR-147 during organ injury, we generated a novel transgenic mouse line with a floxed miR-147 gene and crossed the mice with CMVcre for germline deletion of miR-147. The successful deletion of miR-147 was confirmed as miR$147^{\prime-}$ mice showed completely abolished miR-147 expression under inflammatory conditions. Next, we assessed the reproductive performance and growth curves of the

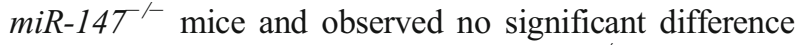
in weight gain between WT and $m i R-14 T^{-1}$ mice. After confirming the successful knockout of miR-147 in several organs following CLP, we next investigated the baseline inflammation in major organs and tissues using RT-qPCR and histological analysis. Results from these analyses suggest that $m i R-147^{-1}$ mice have baseline inflammation and histological characteristics in major organs comparable with WT animals, except an elevated Il6 expression in the spleen. Taken together, these studies confirmed the successful generation of transgenic animals to study the role of miR-147 in organ injury.

MicroRNAs are studied in vivo by several different strategies. First and foremost, pharmacological overexpression and inhibition of microRNAs are essential tools for the 
therapeutic targeting of microRNAs [21]. For instance, delivery of microRNA mimic results in the overexpression of target microRNA and downregulation of the target genes. On the other hand, microRNA inhibition could be achieved by treatment of LNA or antagomirs. Expression of microRNAs in vivo could be achieved by microRNAScope, which will localize and visualize mature microRNAs on tissue slides. Transgenic animal models are instrumental for studying the functional role of microRNAs in vivo, especially models with conditional potential for cell- or tissue-specific manipulation of microRNAs [40]. Transgenic mice could be generated with the injection of a transgene into the fertilized eggs and including an exogenous promoter would facilitate the constitutive or tissue-specific overexpression [41]. Constitutive or conditional knockout of microRNAs could be achieved by gene-targeting vectors using several systems including CreloxP system [42] and flp-FRT system [43]. Moreover, several systems have been established for inducible modification of microRNAs that could also have the potential for inducible knockout or overexpression, including the tetracycline (Tet)-inducible system [44] and the Cre-ER(T) system [45]. Combining the inducible system with the conditional system results in powerful tools to study the temporal and tissuespecific functional role of microRNAs.

Inflammation is commonly observed in many pathogenic conditions including infection, acute organ injury, and chronic organ dysfunctions [46-54]. Initially intended as a response to help resolve tissue injury, inflammation could become excessive and uncontrolled, which leads to further tissue injury and, occasionally, systemic inflammation [5559]. For example, uncontrolled alveolar epithelial inflammation results in ARDS $[1,16,60,61]$, which is the common and main cause of death in COVID-19 [62, 63]. Several previous studies have suggested the importance of endogenous anti-inflammatory pathways for the control of organ inflammation. These pathways include the hypoxiainducible factor signaling pathway $[61,64,65]$, purinergic signaling pathway [66-75], microRNAs [19, 20, 76-78], resolvins [79-81], and many others [82-90]. Along these lines, those pathways not only facilitate tissue protection during pulmonary injuries but also contribute to other inflammatory organ conditions such as myocardial infarction [91-98], kidney injury [99-101], and inflammatory bowel diseases [102-108]. Thus far, the majority of the studies on miR-147 focuses on the regulation of different biological processes such as cell proliferation and drug tolerance in cancer cells [29, 31, 109-112]. Additional studies indicated that miR-147 is crucial for the mechanical stretch-induced apoptosis in myoblast [30]. Moreover, a recent study suggested that miR-147 is reduced during rat myocardial infarction models and overexpression of miR-147 provides cardiac protection [113]. Taken together, miR-147 loxPloxP mice could facility the study of miR-147 in different organs and cell types during inflammatory organ injury by breeding with different $\mathrm{Cre}$ recombinase transgenic mice.

The functional role of miR-147 in inflammation has also been indicated by several studies. For instance, a study from Liu et al. demonstrated that miR-147 overexpression in macrophages could dampen TLR activation-induced cytokine production in vitro [26]. Furthermore, a recent study demonstrated that virulent factor from the Mycobacterium marinum downregulated miR-147 levels and overexpression of miR147 dampened Mycobacterium marinum-induced cytokine production in murine macrophage cell lines in vitro [28]. These studies imply the functional role of miR-147 during infection and inflammatory stimulations in macrophages, and potentially other myeloid cell populations. Our successful generation of floxed miR-147 transgenic mice will facilitate the study of cell-specific function in vivo. Several Cre recombinase mouse lines have been developed to target different populations of macrophages and other myeloid cells $[114,115]$. However, most of these Cre recombinase transgenic mice, including LysM-Cre, Csflr-Cre, CD11b-Cre, F4/ 80-Cre, and CX3CR1-Cre, have limited ability in the specific targeting of a certain myeloid cell population. Recent studies suggested that hCD68-rtTA transgenic system could facilitate the selective and inducible targeting of CD11b+ macrophages, including pulmonary recruited and interstitial macrophages [116-118]. Crossbreeding of miR-147 $7^{\text {loxPloxP }}$ mice with hCD68-rtTA and Teto-Cre mice will facilitate the functional study of miR-147 in macrophages in vivo.

\section{CONCLUSION}

In this study, we have generated a transgenic mouse line with a floxed miR-147 gene $\left(\operatorname{miR}-147^{\text {loxPlloxP }}\right)$ and crossing the miR-147 loxP/oxP mice with CMVcre mice successfully generated mice with germline deletion of

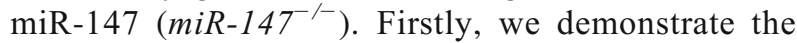
successful deletion of the target gene in different organs under baseline or inflammatory conditions in organs that showed induction of miR-147 during inflammation. Furthermore, we show that $m i R-147^{-/}$mice experience normal growth, development, and off-spring. Moreover, $m i R-147^{-/}$mice have identical baseline inflammatory gene expression compared to C57BL/6 mice, except elevated IL-6 expression in the spleen $(7.5$ fold, $p<0.05)$. Taken together, our data show that we have successfully developed a transgenic animal model for tissue- and cell- 
specific deletion of miR-147 that can be used to study the functional role of miR-147 during inflammation.

\section{ACKNOWLEDGEMENTS}

We would like to acknowledge Yanyu Wang, Ph.D., for critically reviewing the data presented in this manuscript.

\section{AUTHOR CONTRIBUTION}

B. Kim designed and performed the experiments, analyzed the data, and drafted the manuscript. V. Guaregua, X. Chen, C. Zhao, W. Yeow, and N. K. Berg performed the experiments and analyzed the data. H. K. Eltzschig edited the manuscript and provided critical advice on the study. X. Yuan designed and performed the experiments, analyzed the data, and drafted and finalized the manuscript.

\section{FUNDING}

This work is supported by the American Thoracic Society Unrestricted Grant, American Heart Association Career Development Award (19CDA34660279), American Lung Association Catalyst Award (CA-622265), the Center for Clinical and Translational Sciences, McGovern Medical School Pilot Award (1UL1TR003167-01), and Parker B. Francis Fellowship (to X. Yuan); and National Institutes of Health (Bethesda, Maryland) Grant Nos. R01HL154720, R01DK122796, R01DK109574, R01HL133900 and Department of Defense Grant No: W81XWH2110032 (to H. K. Eltzschig).

\section{DATA AVAILABILITY}

The data that support this study are available upon request.

\section{DECLARATIONS}

Ethics Approval. All included studies have approval from the IACUC or CPHS committee at the University of Texas Health Science Center at Houston.

Conflict of Interest. The authors declare no competing interests.

\section{REFERENCES}

1. Williams, G.W., N.K. Berg, A. Reskallah, X. Yuan, and H.K Eltzschig. 2020. Acute respiratory distress syndrome. Anesthesiology 134 (2): 270-282.

2. Jaramillo-Rocha, V. 2017. Acute respiratory distress syndrome. The New England Journal of Medicine 377 (19): 1903-1904.

3. Blanch, L., R. Fernandez, and J. Mancebo. 1995. Acute respiratory distress syndrome. The New England Journal of Medicine 332 (24): 1649 author reply 1650.

4. Eckle, T., and H.K. Eltzschig. 2011. Toll-like receptor signaling during myocardial ischemia. Anesthesiology 114 (3): 490-492.

5. Xia, S., H. Lin, H. Liu, Z. Lu, H. Wang, S. Fan, and N. Li. 2019. Honokiol attenuates sepsis-associated acute kidney injury via the inhibition of oxidative stress and inflammation. Inflammation 42 (3): 826-834.

6. Carney, E.F. 2015. Acute kidney injury: proximal tubule cells modulate inflammation after renal injury. Nature Reviews. $\mathrm{Ne}$ phrology 11 (5): 254.

7. Dirkes, S. 2013. Sepsis and inflammation: impact on acute kidney injury. Nature Reviews Nephrology 40 (2): 125-132 quiz 133.

8. Hotchkiss, R.S., L.L. Moldawer, S.M. Opal, K. Reinhart, I.R. Turnbull, and J.L. Vincent. 2016. Sepsis and septic shock. Nature Reviews. Disease Primers 2: 16045.

9. Cohen, J. 2002. The immunopathogenesis of sepsis. Nature 420 (6917): 885-891.

10. Takeuchi, O., and S. Akira. 2010. Pattern recognition receptors and inflammation. Cell 140 (6): 805-820.

11. Lelubre, C., and J.L. Vincent. 2018. Mechanisms and treatment of organ failure in sepsis. Nature Reviews Nephrology 14 (7): $417-$ 427.

12. Buras, J.A., B. Holzmann, and M. Sitkovsky. 2005. Animal models of sepsis: setting the stage. Nature Reviews Drug Discovery 4 (10): 854-865.

13. Toscano, M.G., D. Ganea, and A.M. Gamero. 2011. Cecal ligation puncture procedure. Journal of Visualized Experiments 51: 2860.

14. Neudecker, V., X. Yuan, J.L. Bowser, and H.K. Eltzschig. 2017. MicroRNAs in mucosal inflammation. Journal of Molecular Medicine (Berlin, Germany) 95 (9): 935-949.

15. Bartel, D.P. 2009. MicroRNAs: target recognition and regulatory functions. Cell 136 (2): 215-233.

16. Lee, L.K., L. Medzikovic, M. Eghbali, H.K. Eltzschig, and X. Yuan. 2020. The role of microRNAs in acute respiratory distress syndrome and sepsis, from targets to therapies: a narrative review. Anesthesia and Analgesia 131: 1471-1484.

17. Lu, W., R. You, X. Yuan, T. Yang, E.L. Samuel, D.C. Marcano, W.K. Sikkema, J.M. Tour, A. Rodriguez, F. Kheradmand, et al. 2015. The microRNA miR-22 inhibits the histone deacetylase HDAC4 to promote $\mathrm{T}(\mathrm{H}) 17$ cell-dependent emphysema. Nature Immunology 16 (11): 1185-1194.

18. Cata, J.P., A. Gorur, X. Yuan, N.K. Berg, A.K. Sood, and H.K. Eltzschig. 2020. Role of micro-RNA for pain after surgery: narrative review of animal and human studies. Anesthesia and Analgesia 130 (6): 1638-1652.

19. Yuan, X., N. Berg, J.W. Lee, T.T. Le, V. Neudecker, N. Jing, and H. Eltzschig. 2018. MicroRNA miR-223 as regulator of innate immunity. Journal of Leukocyte Biology 104 (3): 515-524. 
20. Neudecker, V., K.S. Brodsky, E.T. Clambey, E.P. Schmidt, T.A. Packard, B. Davenport, T.J. Standiford, T. Weng, A.A. Fletcher, L. Barthel, et al. 2017. Neutrophil transfer of miR-223 to lung epithelial cells dampens acute lung injury in mice. Science Translational Medicine 9 (408): eaah5360.

21. Lee, T.J., X. Yuan, K. Kerr, J.Y. Yoo, D.H. Kim, B. Kaur, and H.K. Eltzschig. 2020. Strategies to modulate microRNA functions for the treatment of cancer or organ injury. Pharmacological Reviews 72 (3): 639-667.

22. Jopling, C.L., M. Yi, A.M. Lancaster, S.M. Lemon, and P. Sarnow. 2005. Modulation of hepatitis $C$ virus RNA abundance by a liverspecific MicroRNA. Science 309 (5740): 1577-1581.

23. Janssen, H.L., H.W. Reesink, E.J. Lawitz, S. Zeuzem, M. Rodriguez-Torres, K. Patel, A.J. van der Meer, A.K. Patick, A. Chen, Y. Zhou, et al. 2013. Treatment of HCV infection by targeting microRNA. The New England Journal of Medicine 368 (18): 1685-1694.

24. Bandiera, S., S. Pfeffer, and T.F. Baumert. 2015. Zeisel MB: miR$122-\mathrm{a}$ key factor and therapeutic target in liver disease. Journal of Hepatology 62 (2): 448-457.

25. Zhang, W.C., J.M. Wells, K.H. Chow, H. Huang, M. Yuan, T. Saxena, M.A. Melnick, K. Politi, J.M. Asara, D.B. Costa, C.J. Bult, and F.J. Slack. 2019. miR-147b-mediated TCA cycle dysfunction and pseudohypoxia initiate drug tolerance to EGFR inhibitors in lung adenocarcinoma. Nature Metabolism 1 (4): 460-474.

26. Liu, G., A. Friggeri, Y. Yang, Y.J. Park, and Y. Tsuruta. 2009. Abraham E: miR-147, a microRNA that is induced upon Toll-like receptor stimulation, regulates murine macrophage inflammatory responses. Proceedings of the National Academy of Sciences of the United States of America 106 (37): 15819-15824.

27. Lee, C.G., S. McCarthy, M. Gruidl, C. Timme, and T.J. Yeatman. 2014. MicroRNA-147 induces a mesenchymal-to-epithelial transition (MET) and reverses EGFR inhibitor resistance. PLoS One 9 (1): e84597.

28. Zuo, X., L. Wang, Y. Bao, and J. Sun. 2020. The ESX-1 virulence factors downregulate mir-147-3p in Mycobacterium marinuminfected macrophages. Infection and Immunity 88 (6): e00088$\mathrm{e} 00020$.

29. Zhang, Y., H.E. Zhang, and Z. Liu. 2016. MicroRNA-147 suppresses proliferation, invasion and migration through the AKT/ mTOR signaling pathway in breast cancer. Oncology Letters 11 (1): 405-410.

30. Du, Y., F. Yang, D. Lv, Q. Zhang, and X. Yuan. 2019. MiR-147 inhibits cyclic mechanical stretch-induced apoptosis in L6 myoblasts via ameliorating endoplasmic reticulum stress by targeting BRMS1. Cell Stress \& Chaperones 24 (6): 1151-1161.

31. Zhang, E., Q. Liu, Y. Wang, H. Wang, L. He, X. Jin, and N. Li. 2017. MicroRNA miR-147b promotes tumor growth via targeting UBE2N in hepatocellular carcinoma. Oncotarget 8 (69): 114072114080 .

32. Chu, G., J. Zhang, and X. Chen. 2016. Serum level of microRNA147 as diagnostic biomarker in human non-small cell lung cancer. Journal of Drug Targeting 24 (7): 613-617.

33. Kelly, A., A.M. Grabiec, and M.A. Travis. 2018. Culture of human monocyte-derived macrophages. Methods in Molecular Biology 1784: $1-11$.

34. Flaherty, S., and J.M. Reynolds. 2015. Mouse naive CD4+ T cell isolation and in vitro differentiation into T cell subsets. Journal of Visualized Experiments 98: 52739.

35. Lim, J.F., H. Berger, and I.H. Su. 2016. Isolation and activation of murine lymphocytes. Journal of Visualized Experiments 116: 54596.
36. Mercer, P.F., R.H. Johns, C.J. Scotton, M.A. Krupiczojc, M. Konigshoff, D.C. Howell, R.J. McAnulty, A. Das, A.J. Thorley, T.D. Tetley, et al. 2009. Pulmonary epithelium is a prominent source of proteinase-activated receptor-1-inducible CCL2 in pulmonary fibrosis. American Journal of Respiratory and Critical Care Medicine 179 (5): 414-425.

37. Frey, M.R., K.L. Edelblum, M.T. Mullane, D. Liang, and D.B. Polk. 2009. The ErbB4 growth factor receptor is required for colon epithelial cell survival in the presence of TNF. Gastroenterology 136 (1): 217-226.

38. Ding, W., K. Yousefi, and L.A. Shehadeh. 2018. Isolation, characterization, and high throughput extracellular flux analysis of mouse primary renal tubular epithelial cells. Journal of Visualized Experiments 136: 57718.

39. Zhang, D., Y. Cui, B. Li, X. Luo, B. Li, and Y. Tang. 2017. A comparative study of the characterization of miR-155 in knockout mice. PLoS One 12 (3): 0173487.

40. Pal, A.S., and A.L. Kasinski. 2017. Animal models to study microRNA function. Advances in Cancer Research 135: 53-118.

41. Hanahan, D., E.F. Wagner, and R.D. Palmiter. 2007. The origins of oncomice: a history of the first transgenic mice genetically engineered to develop cancer. Genes \& Development 21 (18): $2258-2270$

42. Xiong, F., Z.Q. Wei, Z.Y. Zhu, and Y.H. Sun. 2013. Targeted expression in zebrafish primordial germ cells by Cre/loxP and Gal4/UAS systems. Marine Biotechnology 15 (5): 526-539.

43. Deng, C.X. 2014. Conditional knockout mouse models of cancer. Cold Spring Harbor Protocols 2014 (12): 1217-1233.

44. Das, A.T., L. Tenenbaum, and B. Berkhout. 2016. Tet-on systems for doxycycline-inducible gene expression. Current Gene Therapy 16 (3): 156-167.

45. Kim, H., M. Kim, S.K. Im, and S. Fang. 2018. Mouse Cre-LoxP system: general principles to determine tissue-specific roles of target genes. Laboratory Animal Research 34 (4): 147-159.

46. Yuan, X., C.Y. Chang, R. You, M. Shan, B.H. Gu, M.C. Madison, G. Diehl, S. Perusich, L.Z. Song, L. Cornwell, et al. 2019. Cigarette smoke-induced reduction of C1q promotes emphysema. JCI Insight 5 (13): e124317.

47. Poth, J.M., K. Brodsky, H. Ehrentraut, A. Grenz, and H.K. Eltzschig. 2013. Transcriptional control of adenosine signaling by hypoxia-inducible transcription factors during ischemic or inflammatory disease. Journal of Molecular Medicine (Berlin, Germany) 91 (2): 183-193.

48. Millien, V.O., W. Lu, G. Mak, X. Yuan, J.M. Knight, P. Porter, F. Kheradmand, and D.B. Corry. 2014. Airway fibrinogenolysis and the initiation of allergic inflammation. Annals of the American Thoracic Society 11 (Suppl 5): S277-S283.

49. Le, T.T., N.K. Berg, M.T. Harting, X. Li, H.K. Eltzschig, and X. Yuan. 2019. Purinergic signaling in pulmonary inflammation. Frontiers in Immunology 10: 1633.

50. Hong, M.J., B.H. Gu, M.C. Madison, C. Landers, H.Y. Tung, M. Kim, X. Yuan, R. You, A.A. Machado, B.E. Gilbert, P. Soroosh, M. Elloso, L. Song, M. Chen, D.B. Corry, G. Diehl, and F. Kheradmand. 2018. Protective role of gammadelta T cells in cigarette smoke and influenza infection. Mucosal Immunology 11 (3): 894-908.

51. Wu, F., J.H. Huang, X.Y. Yuan, W.S. Huang, and Y.H. Chen. 2007. Characterization of immunity induced by M2e of influenza virus. Vaccine 25 (52): 8868-8873.

52. Wu, F., X.Y. Yuan, W.S. Huang, and Y.H. Chen. 2009. Heterosubtypic protection conferred by combined vaccination with M2e peptide and split influenza vaccine. Vaccine 27 (43): 6095-6101. 
53. Wu, F., X.Y. Yuan, J. Li, and Y.H. Chen. 2009. The coadministration of CpG-ODN influenced protective activity of influenza M2e vaccine. Vaccine 27 (32): 4320-4324.

54. Shan, M., X. Yuan, L.Z. Song, L. Roberts, N. Zarinkamar, A. Seryshev, Y. Zhang, S. Hilsenbeck, S.H. Chang, C. Dong, et al. 2012. Cigarette smoke induction of osteopontin (SPP1) mediates $\mathrm{T}(\mathrm{H}) 17$ inflammation in human and experimental emphysema. Science Translational Medicine 4 (117): 117ra1 19.

55. Bhavani, S., X. Yuan, R. You, M. Shan, D. Corry, and F. Kheradmand. 2015. Loss of peripheral tolerance in emphysema. phenotypes, exacerbations, and disease progression. Annals of the American Thoracic Society 12 (Suppl 2): S164-S168.

56. Matthay, M.A., R.L. Zemans, G.A. Zimmerman, Y.M. Arabi, J.R. Beitler, A. Mercat, M. Herridge, A.G. Randolph, and C.S. Calfee. 2019. Acute respiratory distress syndrome. Nature Reviews. Disease Primers 5 (1): 18.

57. Medzhitov, R. 2008. Origin and physiological roles of inflammation. Nature 454 (7203): 428-435.

58. Eltzschig, H.K., M.V. Sitkovsky, and S.C. Robson. 2012. Purinergic signaling during inflammation. The New England Journal of Medicine 367 (24): 2322-2333.

59. Vuerich, M., S. Mukherjee, S.C. Robson, and M.S. Longhi. 2020. Control of gut inflammation by modulation of purinergic signaling. Frontiers in Immunology 11: 1882.

60. Ben Salem, C. 2017. Acute respiratory distress syndrome. The New England Journal of Medicine 377 (19): 1904.

61. Yuan, X., J.W. Lee, J.L. Bowser, V. Neudecker, S. Sridhar, and H.K. Eltzschig. 2018. Targeting hypoxia signaling for perioperative organ injury. Anesthesia and Analgesia 126 (1): 308-321.

62. Briggs, F.B.S., M.A. Gianfrancesco, and M.F. George. 2020. More on Covid-19 in immune-mediated inflammatory diseases. The New England Journal of Medicine 383 (8): 796-797.

63. Cao, X. 2020. COVID-19: immunopathology and its implications for therapy. Nature Reviews. Immunology 20: 269-270.

64. Vohwinkel, C.U., S. Hoegl, and H.K. Eltzschig. 2015. Hypoxia signaling during acute lung injury. Journal of Applied Physiology (Bethesda, MD: 1985) 119 (10): 1157-1163.

65. Eckle, T., K. Brodsky, M. Bonney, T. Packard, J. Han, C.H. Borchers, T.J. Mariani, D.J. Kominsky, M. Mittelbronn, and H.K. Eltzschig. 2013. HIF1A reduces acute lung injury by optimizing carbohydrate metabolism in the alveolar epithelium. PLoS Biology 11 (9): e1001665.

66. Ehrentraut, H., E.T. Clambey, E.N. McNamee, K.S. Brodsky, S.F. Ehrentraut, J.M. Poth, A.K. Riegel, J.A. Westrich, S.P. Colgan, and H.K. Eltzschig. 2013. CD73+ regulatory T cells contribute to adenosine-mediated resolution of acute lung injury. The FASEB Journal 27 (6): 2207-2219.

67. Eckle, T., E.M. Kewley, K.S. Brodsky, E. Tak, S. Bonney, M. Gobel, D. Anderson, L.E. Glover, A.K. Riegel, S.P. Colgan, and H.K. Eltzschig. 2014. Identification of hypoxia-inducible factor HIF-1A as transcriptional regulator of the A2B adenosine receptor during acute lung injury. Journal of Immunology 192 (3): 12491256.

68. Eckle, T., A. Grenz, S. Laucher, and H.K. Eltzschig. 2008. A2B adenosine receptor signaling attenuates acute lung injury by enhancing alveolar fluid clearance in mice. The Journal of Clinical Investigation 118 (10): 3301-3315.

69. Schingnitz, U., K. Hartmann, C.F. Macmanus, T. Eckle, S. Zug, S.P. Colgan, and H.K. Eltzschig. 2010. Signaling through the A2B adenosine receptor dampens endotoxin-induced acute lung injury. Journal of Immunology 184 (9): 5271-5279.

70. Belikoff, B.G., L.J. Vaickus, M. Sitkovsky, and D.G. Remick. 2012. A2B adenosine receptor expression by myeloid cells is proinflammatory in murine allergic-airway inflammation. Journal of Immunology 189 (7): 3707-3713.

71. Antonioli, L., C. Blandizzi, P. Pacher, and G. Hasko. 2019. The purinergic system as a pharmacological target for the treatment of immune-mediated inflammatory diseases. Pharmacological Reviews 71 (3): 345-382.

72. Antonioli, L., P. Pacher, E.S. Vizi, and G. Hasko. 2013. CD39 and CD73 in immunity and inflammation. Trends in Molecular Medicine 19 (6): 355-367.

73. Hasko, G., and B. Cronstein. 2013. Regulation of inflammation by adenosine. Frontiers in Immunology 4: 85.

74. Hasko, G., and B.N. Cronstein. 2004. Adenosine: an endogenous regulator of innate immunity. Trends in Immunology 25 (1): 33-39.

75. He, W., and B.N. Cronstein. 2012. Adenosine A1 receptor regulates osteoclast formation by altering TRAF6/TAK1 signaling. Purinergic Signal 8 (2): 327-337.

76. Wu, X.M., K.Q. Ji, H.Y. Wang, Y. Zhao, J. Jia, X.P. Gao, and B. Zang. 2018. MicroRNA-339-3p alleviates inflammation and edema and suppresses pulmonary microvascular endothelial cell apoptosis in mice with severe acute pancreatitis-associated acute lung injury by regulating Anxa3 via the Akt/mTOR signaling pathway. Journal of Cellular Biochemistry 119 (8): 6704-6714.

77. Xie, T., J. Liang, N. Liu, Q. Wang, Y. Li, P.W. Noble, and D. Jiang. 2012. MicroRNA-127 inhibits lung inflammation by targeting IgG Fcgamma receptor I. Journal of Immunology 188 (5): $2437-2444$.

78. Xue, H., and M.X. Li. 2018. MicroRNA-150 protects against cigarette smoke-induced lung inflammation and airway epithelial cell apoptosis through repressing p53: MicroRNA-150 in CSinduced lung inflammation. Human \& Experimental Toxicology 37 (9): 920-928.

79. Croasdell, A., T.H. Thatcher, R.M. Kottmann, R.A. Colas, J. Dalli, C.N. Serhan, P.J. Sime, and R.P. Phipps. 2015. Resolvins attenuate inflammation and promote resolution in cigarette smoke-exposed human macrophages. American Journal of Physiology. Lung Cellular and Molecular Physiology 309 (8): L888-L901.

80. Abdulnour, R.E., H.P. Sham, D.N. Douda, R.A. Colas, J. Dalli, Y. Bai, X. Ai, C.N. Serhan, and B.D. Levy. 2016. Aspirin-triggered resolvin D1 is produced during self-resolving gram-negative bacterial pneumonia and regulates host immune responses for the resolution of lung inflammation. Mucosal Immunology 9 (5): $1278-1287$.

81. Hsiao, H.M., R.E. Sapinoro, T.H. Thatcher, A. Croasdell, E.P. Levy, R.A. Fulton, K.C. Olsen, S.J. Pollock, C.N. Serhan, R.P. Phipps, and P.J. Sime. 2013. A novel anti-inflammatory and proresolving role for resolvin D1 in acute cigarette smoke-induced lung inflammation. PLoS One 8 (3): e58258.

82. Robb, C.T., K.H. Regan, D.A. Dorward, and A.G. Rossi. 2016. Key mechanisms governing resolution of lung inflammation. Seminars in Immunopathology 38 (4): 425-448.

83. Basil, M.C., and B.D. Levy. 2016. Specialized pro-resolving mediators: endogenous regulators of infection and inflammation. $\mathrm{Na}$ ture Reviews. Immunology 16 (1): 51-67.

84. Serhan, C.N. 2007. Resolution phase of inflammation: novel endogenous anti-inflammatory and proresolving lipid mediators and pathways. Annual Review of Immunology 25: 101-137.

85. Liu, J., J. Du, X. Cheng, X. Zhang, Y. Li, X. Fu, and X. Chen. 2019. Effect of netrin-1 anti-inflammatory factor on acute lung injury in sepsis rats. Medical Science Monitor 25: 7928-7935.

86. Ko, C.L., J.A. Lin, K.Y. Chen, A.C. Hsu, S.Y. Wu, Y.T. Tai, K.H. Lin, W.C. Chung, and M.H. Li. 2019. Netrin-1 dampens hypobaric hypoxia-induced lung injury in mice. High Altitude Medicine \& Biology 20 (3): 293-302. 
87. Mirakaj, V., C.A. Thix, S. Laucher, C. Mielke, J.C. Morote-Garcia, M.A. Schmit, J. Henes, K.E. Unertl, D. Kohler, and P. Rosenberger. 2010. Netrin-1 dampens pulmonary inflammation during acute lung injury. American Journal of Respiratory and Critical Care Medicine 181 (8): 815-824.

88. Li, J., G. Ruffenach, G. Kararigas, C.M. Cunningham, N. Motayagheni, N. Barakai, S. Umar, V. Regitz-Zagrosek, and M. Eghbali. 2017. Intralipid protects the heart in late pregnancy against ischemia/reperfusion injury via Caveolin2/STAT3/GSK3beta pathway. Journal of Molecular and Cellular Cardiology 102: 108-116.

89. Korner, A., M. Schlegel, J. Theurer, H. Frohnmeyer, M. Adolph, M. Heijink, M. Giera, P. Rosenberger, and V. Mirakaj. 2018. Resolution of inflammation and sepsis survival are improved by dietary Omega-3 fatty acids. Cell Death and Differentiation 25 (2): 421-431.

90. Mirakaj, V., J. Dalli, T. Granja, P. Rosenberger, and C.N. Serhan. 2014. Vagus nerve controls resolution and pro-resolving mediators of inflammation. The Journal of Experimental Medicine 211 (6): 1037-1048.

91. Eckle, T., K. Hartmann, S. Bonney, S. Reithel, M. Mittelbronn, L.A. Walker, B.D. Lowes, J. Han, C.H. Borchers, P.M. Buttrick, D.J. Kominsky, S.P. Colgan, and H.K. Eltzschig. 2012. Adora2belicited Per2 stabilization promotes a HIF-dependent metabolic switch crucial for myocardial adaptation to ischemia. Nature Medicine 18 (5): 774-782.

92. Bonney, S., D. Kominsky, K. Brodsky, H. Eltzschig, L. Walker, and T. Eckle. 2013. Cardiac Per2 functions as novel link between fatty acid metabolism and myocardial inflammation during ischemia and reperfusion injury of the heart. PLoS One 8 (8): e71493.

93. Halade, G.V., V. Kain, and C.N. Serhan. 2018. Immune responsive resolvin D1 programs myocardial infarction-induced cardiorenal syndrome in heart failure. The FASEB Journal 32 (7): 3717-3729.

94. Cai, Z.P., N. Parajuli, X. Zheng, and L. Becker. 2012. Remote ischemic preconditioning confers late protection against myocardial ischemia-reperfusion injury in mice by upregulating interleukin-10. Basic Research in Cardiology 107 (4): 277.

95. Eltzschig, H.K., S.K. Bonney, and T. Eckle. 2013. Attenuating myocardial ischemia by targeting A2B adenosine receptors. Trends in Molecular Medicine 19 (6): 345-354.

96. Kain, V., K.A. Ingle, R.A. Colas, J. Dalli, S.D. Prabhu, C.N. Serhan, M. Joshi, and G.V. Halade. 2015. Resolvin D1 activates the inflammation resolving response at splenic and ventricular site following myocardial infarction leading to improved ventricular function. Journal of Molecular and Cellular Cardiology 84: 2435 .

97. Koeppen, M., J.W. Lee, S.W. Seo, K.S. Brodsky, S. Kreth, I.V. Yang, P.M. Buttrick, T. Eckle, and H.K. Eltzschig. 2018. Hypoxiainducible factor 2-alpha-dependent induction of amphiregulin dampens myocardial ischemia-reperfusion injury. Nature Coтmunications 9 (1): 816.

98. Kohler, D., T. Eckle, M. Faigle, A. Grenz, M. Mittelbronn, S. Laucher, M.L. Hart, S.C. Robson, C.E. Muller, and H.K. Eltzschig. 2007. CD39/ectonucleoside triphosphate diphosphohydrolase 1 provides myocardial protection during cardiac ischemia/ reperfusion injury. Circulation 116 (16): 1784-1794.

99. Duffield, J.S., S. Hong, V.S. Vaidya, Y. Lu, G. Fredman, C.N. Serhan, and J.V. Bonventre. 2006. Resolvin D series and protectin D1 mitigate acute kidney injury. Journal of Immunology 177 (9): 5902-5911.

100. Zarbock, A., C. Schmidt, H. Van Aken, C. Wempe, S. Martens, P.K. Zahn, B. Wolf, U. Goebel, C.I. Schwer, P. Rosenberger, et al. 2015. Effect of remote ischemic preconditioning on kidney injury among high-risk patients undergoing cardiac surgery: a randomized clinical trial. JAMA 313 (21): 2133-2141.

101. Carney, E.F. 2012. Diabetic nephropathy: Netrin-1 expression in proximal tubular epithelial cells protects against kidney inflammation and injury. Nature Reviews. Nephrology 8 (12): 681.

102. Arita, M., M. Yoshida, S. Hong, E. Tjonahen, J.N. Glickman, N.A. Petasis, R.S. Blumberg, and C.N. Serhan. 2005. Resolvin E1, an endogenous lipid mediator derived from omega-3 eicosapentaenoic acid, protects against 2,4,6-trinitrobenzene sulfonic acid-induced colitis. Proceedings of the National Academy of Sciences of the United States of America 102 (21): 7671-7676.

103. Ishida, T., M. Yoshida, M. Arita, Y. Nishitani, S. Nishiumi, A. Masuda, S. Mizuno, T. Takagawa, Y. Morita, H. Kutsumi, H. Inokuchi, C.N. Serhan, R.S. Blumberg, and T. Azuma. 2010. Resolvin E1, an endogenous lipid mediator derived from eicosapentaenoic acid, prevents dextran sulfate sodium-induced colitis. Inflammatory Bowel Diseases 16 (1): 87-95.

104. Bowser, J.L., L.H. Phan, and H.K. Eltzschig. 2018. The hypoxiaadenosine link during intestinal inflammation. Journal of Immunology 200 (3): 897-907.

105. Aherne, C.M., C.B. Collins, and H.K. Eltzschig. 2013. Netrin-1 guides inflammatory cell migration to control mucosal immune responses during intestinal inflammation. Tissue Barriers 1 (2): e24957.

106. Eltzschig, H.K., J. Rivera-Nieves, and S.P. Colgan. 2009. Targeting the A2B adenosine receptor during gastrointestinal ischemia and inflammation. Expert Opinion on Therapeutic Targets 13 (11): 1267-1277.

107. Grenz, A., E. Clambey, and H.K. Eltzschig. 2012. Hypoxia signaling during intestinal ischemia and inflammation. Current Opinion in Critical Care 18 (2): 178-185.

108. Morote-Garcia, J.C., P. Rosenberger, N.M. Nivillac, I.R. Coe, and H.K. Eltzschig. 2009. Hypoxia-inducible factor-dependent repression of equilibrative nucleoside transporter 2 attenuates mucosal inflammation during intestinal hypoxia. Gastroenterology 136 (2): 607-618.

109. Li, Z.Y., L. Yang, X.J. Liu, X.Z. Wang, Y.X. Pan, and J.M. Luo. 2018. The long noncoding RNA MEG3 and its target miR-147 regulate JAK/STAT pathway in advanced chronic myeloid leukemia. EBioMedicine 34: 61-75.

110. Ning, X., C. Wang, M. Zhang, and K. Wang. 2019. Ectopic expression of miR-147 inhibits stem cell marker and epithelialmesenchymal transition (EMT)-related protein expression in colon cancer cells. Oncology Research 27 (4): 399-406.

111. Shen, J., W. Niu, H. Zhang, M. Jun, and H. Zhang. 2018. Downregulation of microRNA-147 inhibits cell proliferation and increases the chemosensitivity of gastric cancer cells to 5fluorouracil by directly targeting PTEN. Oncology Research 26 (6): 901-911.

112. Li, F., X. Wang, and L. Yang. 2020. MicroRNA-147 targets BDNF to inhibit cell proliferation, migration and invasion in non-small cell lung cancer. Oncology Letters 20 (2): 1931-1937.

113. Wu, C.G., and C. Huang. 2020. MicroRNA-147 inhibits myocardial inflammation and apoptosis following myocardial infarction via targeting HIPK2. European Review for Medical and Pharmacological Sciences 24 (11): 6279-6287.

114. Abram, C.L., G.L. Roberge, Y. Hu, and C.A. Lowell. 2014. Comparative analysis of the efficiency and specificity of myeloid-Cre deleting strains using ROSA-EYFP reporter mice. Journal of Immunological Methods 408: 89-100.

115. Shi, J., L. Hua, D. Harmer, P. Li, and G. Ren. 2018. Cre driver mice targeting macrophages. Methods in Molecular Biology 1784: 263 275 . 
116. McCubbrey, A.L., L. Barthel, K.J. Mould, M.P. Mohning, E.F. Redente, and W.J. Janssen. 2016. Selective and inducible targeting of $\mathrm{CD} 11 \mathrm{~b}+$ mononuclear phagocytes in the murine lung with hCD68-rtTA transgenic systems. American Journal of Physiology. Lung Cellular and Molecular Physiology 311 (1): L87-L100.

117. Iqbal, A.J., E. McNeill, T.S. Kapellos, D. Regan-Komito, S. Norman, S. Burd, N. Smart, D.E. Machemer, E. Stylianou, H. McShane, et al. 2014. Human CD68 promoter GFP transgenic mice allow analysis of monocyte to macrophage differentiation in vivo. Blood 124 (15): e33-e44.

118. Pillai, M.M., B. Hayes, and B. Torok-Storb. 2009. Inducible transgenes under the control of the hCD68 promoter identifies mouse macrophages with a distribution that differs from the F4/ 80 - and CSF-1R-expressing populations. Experimental Hematology 37 (12): 1387-1392.

Publisher's Note Springer Nature remains neutral with regard to jurisdictional claims in published maps and institutional affiliations. 